\title{
Recurrent Minor Salivary Gland Adenocarcinoma
}

National Cancer Institute

\section{Source}

National Cancer Institute. Recurrent Minor Salivary Gland Adenocarcinoma. NCI

Thesaurus. Code C153612.

The reemergence of minor salivary gland adenocarcinoma after a period of remission. 